\title{
Fluoride levels in bottled water
}

\author{
Fluoride content of still bottled waters available in the North-East of England, UK
}

F. V. Zohouri, A. Maguire and P. J. Moynihan Br Dent J 2003; 195: 515-518

Objective

The aims of this study were to measure the fluoride content of still bottled waters on sale in the UK and to estimate and compare the fluoride intake from tap and bottled water for British children.

\section{Methods}

Three bottles of 25 commercial brands of bottled water were purchased from supermarkets, grocery stores and health shops in the North-East of England. All samples were still spring, mineral or distilled waters, sold in plastic bottles. The fluoride content of all samples was determined, in duplicate, using a Fluoride Ion Selective Electrode.

\section{Results}

The mean $( \pm$ SD) fluoride content of the bottled waters was $0.08( \pm 0.08) \mathrm{mg} \mathrm{L}^{-1}$ with a range from $0.01-0.37 \mathrm{mg} \mathrm{L}^{-1}$ which is below the accepted standard for optimally fluoridated water. The mean fluoride intake for 4-18-year-olds when the source of water intake is solely fluoridated tap water was estimated to be $0.26 \mathrm{mg} \mathrm{F}$ per day; compared with $0.16 \mathrm{mg} F$ per day, when a combination of tap and bottled water is consumed.

\section{Conclusions}

Bottled water, from those samples, is unlikely to make an important contribution to total fluoride intake in British diets. Consumption of bottled water containing a negligible amount of fluoride in preference to fluoridated tap water might result in less than optimal fluoride ingestion in young people.

\section{IN BRIEF}

- Mean fluoride content of all bottled waters sampled was below the accepted standard for optimally fluoridated water.

- A lack of agreement between the measured fluoride concentration and that displayed on the labels was observed in three-quarters of the samples.

- When advising children and parent/carers on fluoride therapy, the source of their drinking water (ie tap or boiled) should be taken into consideration.

- The dental health of a child who drinks bottled waters containing a low level of fluoride, as the main source of drinking water, might be affected as a result of receiving a sub-optimal level of fluoride.

\section{COMMENT}

The appropriate use of fluoride has been responsible for much of the marked improvement in oral health in this country and abroad. Drinking water is the main vehicle for dietary fluoride and, as the authors of the article say, about $12 \%$ of the UK population receive optimally fluoridated water from the public mains supply. This paper tells us of the great increase in the purchase of bottled water in this country and the prediction that this trend will continue. The inroads that bottled water had made on drinking water intake of UK children some five years ago is illustrated in this paper. Since the authors found that still bottled water contained low concentrations of fluoride, a reduced fluoride intake in people choosing to consume bottled water rather than water from a fluoridated public water supply, can be seen. The paper discusses the implications of this trend for both the dental practitioner and the public health planner.

Similar reports were published in the British Dental Journal in 1982 and 1994. Since the bottled water market is developing rapidly, regular updates are welcome. This survey was limited to still plain water in plastic bottles. There are other bottled (and canned) drinks which are consumed instead of tap water - for example, aerated drinks, those sold in glass bottles and flavoured soft drinks. It would be useful if similar information on fluoride concentration (and $\mathrm{pH}$ ) of these drinks could be published in the future. The use of water filters in houses is also increasing and there is a need for more information on their effect on fluoride (and other mineral) concentration and $\mathrm{pH}$ of household water. The issue of $\mathrm{pH}$ was highlighted in recent correspondence to the journal and it is reassuring to note the high $\mathrm{pH}$ of bottled water, in the present article.

The results of this survey will be of interest to those who advise parents and carers of infants. There is a trend for milk formula feeds to be made up with bottled water. Excessive fluoride ingestion by these infants could occur if this bottled water had a high fluoride concentration - this study has shown that this is unlikely to occur.

Andrew Rugg-Gunn, Professor Emeritus, Newcastle University doi:10.1038/sj.bdj.4810666 